\title{
Automatic Control Mechanism for Grinding Process Based on KingView and PLC System
}

\author{
Wang Deyan \\ City College , Kunming University of Science and Technology, Kunming650093, China \\ 175364179@qq.com
}

\begin{abstract}
This article based on grinding technology production processes and requirements, according to the KingView analysis, based on PLC control principle, to design a new algorithm suitable for grinding process that can achieve automatic control, then the grinding process can be entire automatic control in beneficiation process, ensure normal production. First, frequency converter regulators into first grinding machine ore amount, and the energy-saving purpose come true. In the whole process of dressing and grinding, the main control to mine is mineral feeding control and mineral grinding machine's mineral feeding, mineral eliminating and the concentration. The system has three monitoring; monitoring equipment on the site, field data collection, remote equipment monitoring. At first, equipment on the site is controlled by on-site PLC. a. External devices and databases: Definite alarm system, variable, and so on. Stored in the database is the current value of the variables, the variables include system variables and user-defined variables. The application of PLC technology and KingView has optimized the structure of the automatic control system, the rational allocation of the control system greatly reduces the cost of production, it is the beneficiation plant control system to achieve protection.
\end{abstract}

Keywords-grinding; automatic control; PLC system; KingView; Mineral processing

\section{INTRODUCTION}

21st century, the mineral resource on Earth is constantly reduced. At the same time, there is fierce mining market competition increasingly. Effective use of limited resources is an extremely urgency for the various enterprises. To achieve the production process information, automation is the only way to progress for mining reform, production management. In recent years, the domestic enterprise management of information technology, production process automation, the equipment level of intelligent greatly enhanced. Many large companies do application integration, collectivity development, integration to the tube - control, Contemporary Integrated Manufacturing System for the individual development, in particular, the overall level of automation of large-scale mineral processing enterprises increased rapidly, the performance is also very obvious.

Beneficiation processes to the mining, crushing, grinding etc[1,2]. several major processes in the metallurgical industry. Beneficiation process, the poor production environment, the level of automation need to be improved, some even run through artificial judgment, and then proceed to the relevant regulation. As the regulation is not timely, the running is unstable; often enable the mill to appear "fasting" or "bloating" phenomenon, then affecting the quality of the entire process of production and operating costs. Based on these, the concentrator automatic control system is of great significance. Recent research is mainly the combination of computer technology and advanced measurement and control instrumentation, and the introduction of modern control theory and artificial intelligence techniques, so that the mineral processing control technology to achieve a higher level. Have a more successful application in detection technology, mineral processing modeling and simulation, process control (PID, multi-variable optimization, intelligent) and computer technology [3, 4].

At present, many domestic and foreign experts and scholars have developed some excellent configuration control system, such as configuration Wang Application of King view 6.52 and Siemens WinCC 6.0[5]. This article based on PLC controller, analysis the dressing of the grinding process, and designs a simple but practical automatic control system.

\section{MINERAL PROCESSING FLOWSHEET}

In the whole process of dressing and grinding, the main control to mine is mineral feeding control and mineral grinding machine's mineral feeding, mineral eliminating and the concentration.

First of all, the original ore become coarse crushing after use crushing machine crumble it, then transported by belt conveyor to the next machine to carry out further crumbling and make it broken bits.

The broken bits then will be transported by conveyor to the intermediate warehouse to temporary storage, and then the broken bits will be filtered by the vibrating screen, below the vibrating screen is finished mine, and other broken bits will be transported by belt conveyor to crushing machine to make it broken bits again.

After it, let the finished mine to smashing warehouse transported by unloading tools, and transport by belt 
conveyor to the grinding machine for grinding processing, then floating the pulp that eliminated by grinding machine. In the end, this completes the dressing process

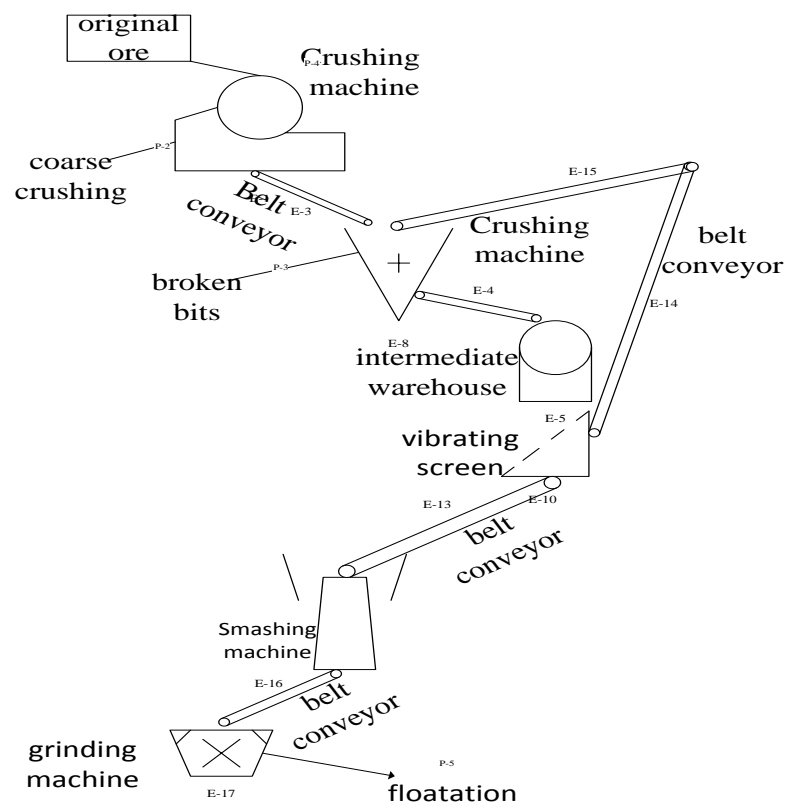

Figure 1. mineral processing flowsheet

\section{PLC AND KINGVIEW INTRODUCTION}

PLC is a programmable logic controller. It uses a programmable Memory, for its internal storage procedures; perform logical operations, sequential control, timing counting and arithmetic operation etc[6,7]. user-oriented instructions, and digital or analog I / O control various types of machinery or production processes. PLC in real terms is a dedicated industrial control computer, the hardware structure is basically the same with the micro-computer, and the basic composition is: power supply, central processing unit, Memory, I/O interface circuit, functional modules, and communication modules. The PLC ' form is flexible, easy expansion, easy to use, simple programming, and can adapt to various harsh environment, it has anti-interference ability and reliability.

TABLE I. Major PLC components of the system selected

\begin{tabular}{ccc}
\hline PLC module & Model & Function Description \\
\hline $\begin{array}{c}\text { CPU module } \\
\text { Power supply } \\
\text { module } \\
\begin{array}{c}\text { Analog input } \\
\text { module }\end{array}\end{array}$ & PSU312 & $\begin{array}{c}\text { Management, } \\
\text { instruction }\end{array}$ \\
$\begin{array}{c}\text { Analog output } \\
\text { module }\end{array}$ & SM331-AI8 & $\begin{array}{c}\text { Output 24VDC } \\
\text { current, temperature }\end{array}$ \\
$\begin{array}{c}\text { Digital input } \\
\text { module }\end{array}$ & SM321- & $\begin{array}{c}\text { Control of feeder } \\
\text { automatically, run }\end{array}$ \\
DI16 & status \\
\hline
\end{tabular}

\begin{tabular}{ccc}
\hline Digital output & SM322- & Master alarm, parking \\
module & DO16 & PLC and PC \\
$\begin{array}{c}\text { Communication } \\
\text { cards }\end{array}$ & CP5611 & communication \\
\hline
\end{tabular}

Kingview developed by Limited development company of Beijing Asia Control automation software, the software designed by Lin Wei, a dozen engineers developed it after five years. Kingview is a ease of use, openness and integration capabilities of the generic configuration software, running on the Microsoft Windows platform Chinese and has the Chinese interface configuration software, it use a multithreaded, COM component technology to achieve real-time multi-task, the software is stable and reliable[8].

KingView has an integrated development environment: KingView engineering browser. In the project browser can view the various components of the project, and can use to construct the database, defined external device. Use the KingView software development has the following characteristics: (1) experiments all software, simply use the existing computer can complete course of the experiment of automatic control systems, thus greatly reducing the funding to acquire equipment. (2) The system is a Chinese language interface, with a friendly interface, the results of the advantages of visualization. For users, the operation is easy to learn and simple programming and flexible parameter input and modify multiple or repeat the simulation run control capabilities. In addition, it can be visually displayed real-time trend curves of the control system before or after parameter change. The strong ability to interact in the experiment of the automatic control system can play an ideal Effect.

In the process of the preparation of applications using the KingView development system, we should consider the following three aspects: (1) graphics, with abstract graphics to simulate the actual industrial field and appropriate industrial equipment. (2) Data, is to create a specific database, and the variables in this database describe various properties of the IPC object, such as level, flow, etc[9]. (3) connected, is the pixels on the screen what kind of animation to simulate the operation of field devices, as well as how to allow the operator to input control device instructions.

\section{GRINDING AUTOMATIC MONITORING}

In this paper, the design of the control system uses PLC, inverter, radar grain meter, nuclear belt scales and so on, so that it has the entire automatic control in beneficiation process, ensure normal production. First, frequency converter regulators into first grinding machine ore amount, and the energy-saving purpose come true. The system has three monitoring; monitoring equipment on the site, field data collection, remote equipment monitoring. At first, equipment on the site is controlled by on-site PLC. Field data collected by the PLC upload to site acquisition computer, installed on your computer configuration Software by setting 
collection data and status. RMON computer complete same that also configuration software on the computer.

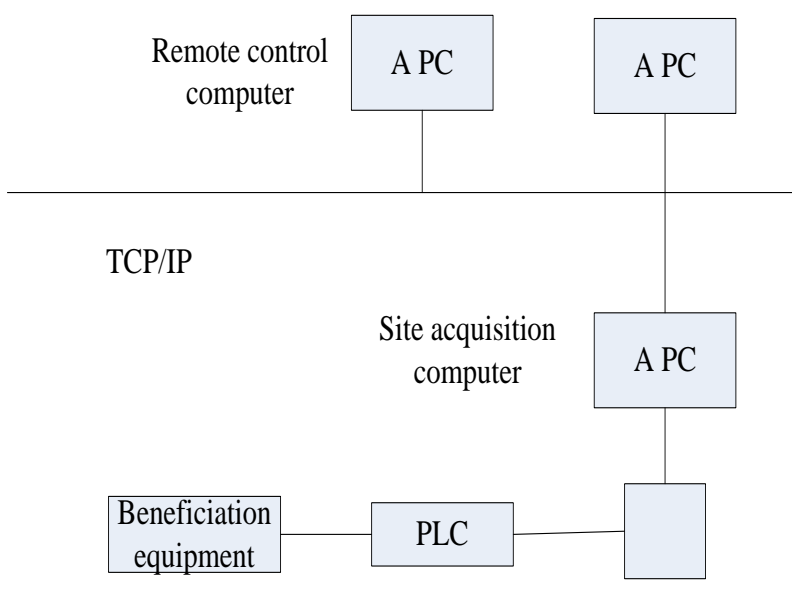

Figure 2. System architecture

\section{A. KingView control}

a. External devices and databases: Definite alarm system, variable, and so on. Kingview let those equipment or procedures who need to exchange data with it as external devices. External equipment includes PLC, instrumentation, modules, boards, inverter, and so on, they generally through the serial port and the host computer to exchange data. After define the external device, the KingView can exchange data with them through I / O variables. Database is the Kingview's core part, when the KingView runs, the production status of the industrial scene reflected the form through animation on the screen. At the same time, directives issued by the engineering staff in front of the computer should quickly reach the production site, it can be said that the database is the machine bridge that contact the PC and the next bit machine. Stored in the database is the current value of the variables, the variables include system variables and user-defined variables. The set of variables recorded the data variable's detailed information that all users can use.

b. Graphical interface: Many kinds of monitor screen and operation screen compose the monitoring software, including the overview screen, flow charts screen, trends graph, reports manage, report production, Print output, operating adjustments and so on. The interface of this monitoring system is: 1. main start screen, 2. feed window, 3. Concentration curve window, 4. Alarm window, 5. Parameter settings, 6. Historical inquiries, and so on.

c. Create an animation connection: The animation connection is to create a screen image and the corresponding relations of the database variables. In this way, the industrial field data, such as the concentration of ore position in a high degree, and so on, when they change through the I / O interface, will cause the change of variables in real-time database. Animation to connect the lead access is a major breakthrough in design man-machine interface, its engineering staff from the duplication of graphics programming freed, for the engineering staff to mention for standard industrial control graphical interface, and connected by programmable command language to enhance the functionality of the graphical interface. KingView system is also connected by some animated graphic objects set access permissions, this has significant meaning for the protection of system security Justice.

\section{B. Equipment composition}

System equipment's basic configuration as follows:

1. One IPC610;

2. KingView 6.5 software;

3. FX2N PLC;

4. I/O wiring board, some wire.

\section{Switch control}

Based the characteristics of beneficiation process, field devices need automatically and chain control. Beneficiation process can be divided into crushing section and grinding segment, when its start in a different way, we can control it through the PLC. Crushing section and grinding segments can be set to "chain / non-chain" and "automatic / manual" two control modes, total four states can choose.

\section{Feed control}

There are two ways to feed when the unloading car feed by automatic control of the process: feed at any time and feed from time to time. The operator can have a way that can be selected according to the production of health and production management needs. At the same time, the whole crushing process and feed can get the interlock control. Among them, every ore bin upload a switch, used to determine the location of the discharge car during operation, and also equipped with limit switches at both ends of the ore bin, that used to control unloading car no boundaries.

(a) Feed from time to time: at regular intervals feed the ore bin some time, during it, if receive the silo cap signal, then stop to feed. The time interval to feed can be set, and can be modified.

(b) Feed at any time: feed the ore bin at any time let the silo lower limit signal the feed signal. When the ore bin's lower limit signal is issued, then feed the ore bin, still the ore bin reach the ceiling.

(c) Feed interlock control: like the process flow diagram shown in Fig . 2-1, each piece of equipment delay start, and the delay time can be set and modify, so that the large electrical equipment will not start at the same time. Then it can reduce the power consumption pressure. When stop feed, operate in reverse order, and each device delay to stop, the delay time can also be set and modify. Interlock control process can achieve fault interlocking control. When a device fails, it should be stopped immediately in the feed; also we should stop all devices. To make the system control stable, while silo's lower limit, up limit signal and fault signal appear after a period of time, we consider this signal is 
valid, then stop feed or down, in order to avoid operational errors, resulting in economic losses.

\section{E. grinding control}

The grinding control is a key step in the process of dressing production, if we can control the grinding process, saving energy, then improving the quality of the final product and production is significant[10]. Among them, control the pulp's concentration in grinding machine is very important. We can determine the water from the amount of ore, making the two proportional. We can also set the upper and lower limits of the concentration of the slurry to achieve an automatic control to slurry concentration. At the same time, we should monitor the status of the grinding machine; the main Monitor is the mill's pressure, temperature, load, system interlock protection and so on.

\section{F. Alarm function}

When there is an accident or failure occurs, the host computer will make a voice alarm through the external speakers, while it can also give the text tip on the display screen. Alarm interface can also set the upper limit of the alarm on the ceiling, lower limit, and under the lower limit, when it exceeds the limit that set range, it will alarm so that it will ensure the safe operation of the system. The alarm interface can display a variety of information, for example: History alarm time, alarm variables, alarm type, alarm handling, and so on. And different levels of alarm are available in different colors, very visually. Of course, if you do not need voice prompt, you can always turn off the voice alarm function, and only through text or symbols to prompt alarm. When the alarm information is more available, you can use the "page up" button and "page down" button to view. In addition, you can point" Acknowledge Alarm " button to clear alarm.

\section{CONCLUSION}

At present, the automatic monitoring of the grinding has become a hot topic, how to efficiently use the limited resources of the mining, is placed in front of everyone's problem. The application of PLC technology has optimized the structure of the automatic control system, the rational allocation of the control system greatly reduces the cost of production, it is the beneficiation plant control system to achieve protection. At the same time, the KingView used in mining has get lots of people's attentions. The KingView let the flow decentralized control, centralized management and control system is reliable, feature-rich, and automatically adjust according to the situation to the amount of ore, and virtually unattended operation of the crushing. In addition, KingView has a good user interface, parameter adjustment is simple, easy to operate, has brought great economic benefits to the dressing and grinding

\section{REFERENCES}

[1] Wang Zhaoqian, Wang Xingliang, Yin Bin, and so on: The Crusher controller development and application [J]. Gold mines, 2001 (11): 35 - 35(in Chinese);

[2] Wang Fengyu, Zhang Qin, Huang Songwei. Beneficiation Automation Review [J]. Foreign metal ores beneficiation, 2006 (8): 18 - 21(in Chinese);

[3] Tangsathitkulchai C. Effects of Slurry Concentration and Powder Filling on the Net Mill Power of a Laboratory Ball Mill [J]. Powder Technology: (S0032-5910), 2003, 137(3): 131-138.

[4] Chen Xi-song. Constrained Model Predictive Control in Ball-mill Grinding Process [J]. Powder Technology, 2008, 18(6): 31-39.

[5] Ren Junjie Li Hongxing, Li Yuan: Based on PLC and KingView of control experimental system[J]. Laboratory Research and Exploration, 2010,29 (5) :16-19 (in Chinese);

[6] OPC Fundation: OPC Data Access Specification 1.0A[S]. 1997;

[7] Kevin Collins. PLC Programming for Industrial Automation[M] . Exposure Publishing, 2007;

[8] [Ma Guohua: monitoring KingView software and its use [S]. Tsinghua University Press, 2001. (in Chinese);

[9] Xue Yingcheng, He Jianqiang: IPC and KingView control principles and applications (Second Edition) [S]. China Electric Power Press, 2011 (in Chinese);

[10] Song Wei, Li Wenguang: Grinding and classification operations intelligent control and network monitoring $[\mathrm{J}]$. China Mining and Construction, 2004,33 (3) :34-37(in Chinese). 